\title{
Utilizing Online Exams: A Case Study
}

Stacy M.P. Schmidt, Ed.D., California State University, Bakersfield, USA

David L. Ralph, Ph.D., Pepperdine University, USA

Bruce Buskirk, Ph.D., Pepperdine University, USA

\begin{abstract}
Technology has opened a wide range of possibilities for the college classroom. Thus, the classroom has changed in a variety of ways. Some courses have been converted to fully online courses. Students and instructors do not have any face-to-face contact in these courses. Other courses have converted a portion of their courses to online. These classes are generally referred to as Hybrid classes. Students and instructors meet face-to-face for a portion of the course and complete online assignments for the remainder of the course. Some other courses have maintained their face-to-face course but have integrated technology into those courses.

Instructors have utilized a variety of technologies that include but are not limited to: Live Chats, Threaded Discussions - Forums, Powerpoint Presentations, Email, Videos, Software, Spreadsheets, Word Processors, Online Portals, Electronic Portfolios/Projects, Online Exams.

This is a case study of the implementation of online exams in a traditional classroom. Students are given a paper and pencil exam that has been utilized previously in other courses as the midterm. Then an online exam was utilized in the courses. The case study looks at the success of the exam from the point of view of the students and instructors. Students overwhelmingly indicated that the online exam was superior to the paper exam. Students indicated that the online exams provided an opportunity for students to complete the exam at a time that was best for them. They were able to pick a time that reduced anxiety. The online exam also provided immediate feedback on how they did. Faculty indicated that although the online exam does have a few glitches and there are concerns about cheating, it was effective and proved useful. Further studies need to be done regarding the online exam to assure that it is an accurate evaluation of student learning.
\end{abstract}

Keywords: exams, online, internet, professor, portals

\section{INTRODUCTION}

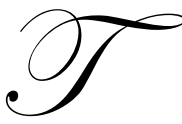

echnology has opened a wide range of possibilities for the college classroom. Thus, the classroom has changed in a variety of ways. Some courses have been converted to fully online courses. Students and instructors do not have any face-to-face contact in these courses. Other courses have converted a portion of their courses to online. These classes are generally referred to as Hybrid classes. Students and instructors meet face-to-face for a portion of the course and complete online assignments for the remainder of the course. Some other courses have maintained their face-to-face course but have integrated technology into those courses.

Instructors have utilized a variety of technologies that include but are not limited to:

- $\quad$ Live Chats

- $\quad$ Threaded Discussions - Forums

- $\quad$ Powerpoint Presentations 


$\begin{array}{ll}\text { - } & \text { Email } \\ \text { - } & \text { Videos } \\ \text { - } & \text { Software } \\ \text { - } & \text { Spreadsheets } \\ \text { - } & \text { Onord Processors } \\ \text { - } & \text { Electronic Portals } \\ \text { - } & \text { Online Exams }\end{array}$

This is a case study of the implementation of online exams in a traditional classroom. Students in two courses are given two exams a midterm and a final. Students are given a paper exam that has been utilized previously in other courses as the midterm. Then an online exam was utilized in the courses for their Final Exam. The case study looks at the success of the online exam from the point of view of the students and instructors.

\section{LITERATURE REVIEW}

A literature review revealed research and studies based on implementation of a variety technologies in college courses. "The internet has opened many possibilities for the classroom instruction but it can also be a barrier to teaching as well" (Bugeja, 2006). The new innovative technologies provide opportunities to improve learning and create a more exciting and motivating environment (Connors, 2007).

According to a case study by Ralph, Buskirk, and Schmidt (2007) regarding the use of online projects, students in favor of online projects indicated that the accessibility to the professor for fast and easy feedback was a great asset. Futhermore, the study revealed that when implementing technology students were concerned with the expense of the technology, the necessity for internet access, and the reliability of the technology.

Research on student perceptions and satisfaction with online courses provide insights to student reactions and satisfaction with implementation of an online exam. Hale (2007) found that student satisfaction surveys reveal that the most important reason for taking a distance education course is its convenience. In addition, Steinman (2007) indicated that "students' perceptions of online courses can be negative if they experience large transactional distance with the instructor and with other students and can influence whether a student will stay in or drop out of a class."

Steinman (2007) also found that "many students choose to enroll in online courses and the demand for online courses is high. Taking an online course can provide educational experiences that would otherwise be unavailable, especially for students who live in rural areas and do not have convenient access to schools." Rowh (2007) also found that "online courses offer convenient learning and that students who take online classes are working hard. They're just doing it at their own pace, on a schedule and in a setting that works for them."

Walker (2007) indicates that the "widespread availability of computers and the Internet provide considerable enrichment in terms of variety of material and formats for presentation over what was possible with the old correspondence courses". The Chronicle for Higher Education (2007) reported that a university stated that they "use electronic education to add on to their curriculum, not as the main basis." This lends to the implementation of an online exam into a traditional classroom where students still get the face-to-face interaction with the instructor and classmates but the control of time and location to take their exams.

Patterson (2006) conducted a post-examination survey of students completing an online exam. The study "found a large majority of students were able to easily access the online exam, found the testing tool easy to use, and were able to complete the comprehensive exam with little difficulty. The future use of online assessment for the comprehensive exam was supported by $87 \%$ of respondents." Furthermore, Patterson found that the "Web-based comprehensive exam procedures employed made it possible for students to take the exam at the time and place of their choosing". The exam was able to reduce stress for students by giving them the ability to choose time and location of taking the exam according to Patterson. Patterson (2006) also acknowledged that the "challenges to test items security and the creation of procedures to minimize the possibility of collaboration and cheating on this type 
of "high-stakes" examination remains to be fully met.

A study of online exams by Luecht (2001) "identified six challenges of Webbased testing: (1) test-taker identity and testing materials security risks, (2) measurement of problem-solving and complex skills, (3) implementation of advanced item selection and test construction algorithms, (4) management and processing of test response data, (5) deployment of "high-bandwidth" multimedia tests and, (6) optimization of the "usability" of Webbased testing interfaces." Luecht (2001) also identified several "strengths of Web-based testing including rapid test development and deployment, around-the-clock test access, prompt results reporting, and decreased need for test administration personnel."

A study by Hay (2002) reports that an online exam is one in which questions are answered on, stored on and often marked by computers. Hay discovered the following keys to taking an online exam:

- Do not be tempted to access software other than that prescribed during the exam

- $\quad$ Sometimes attempting to use other packages interferes with the exam software, thereby jeopardising your answers

- $\quad$ Even if you have finished your exam and are waiting to leave it is unwise to use the computer in any ways other than those required for the exam.

\section{METHODOLOGY, RESULTS, AND IMPLICATIONS}

Two classes were utilized as a case study for implementing an online exam. The course already uses a computer simulation and although it is not required the courses have an online forum available for students use if they choose. The students are given two exams during the course: a midterm and a final. A total of 49 students participated in the two exams. The Midterm Exam covered eleven chapters of the textbook. The Midterm Exam consisted of 60 multiple choice questions generated from a textbook testbank. Two versions of the exam were created one for each class. The questions on the exam were in order with the textbook. Students were given 3 hours to complete the exam and were allowed to use their textbooks and notes on the exam. The exam was administered during the regular class session and the students took the traditional paper and pencil exam. The instructor collected the exams at the end of the three hour time limit, hand scored them, and returned the following week in class.

The Midterm Exam resulted in 22 - As, 18 - Bs, 6- Cs, 1 - D and 2-Fs (See Figure 1).

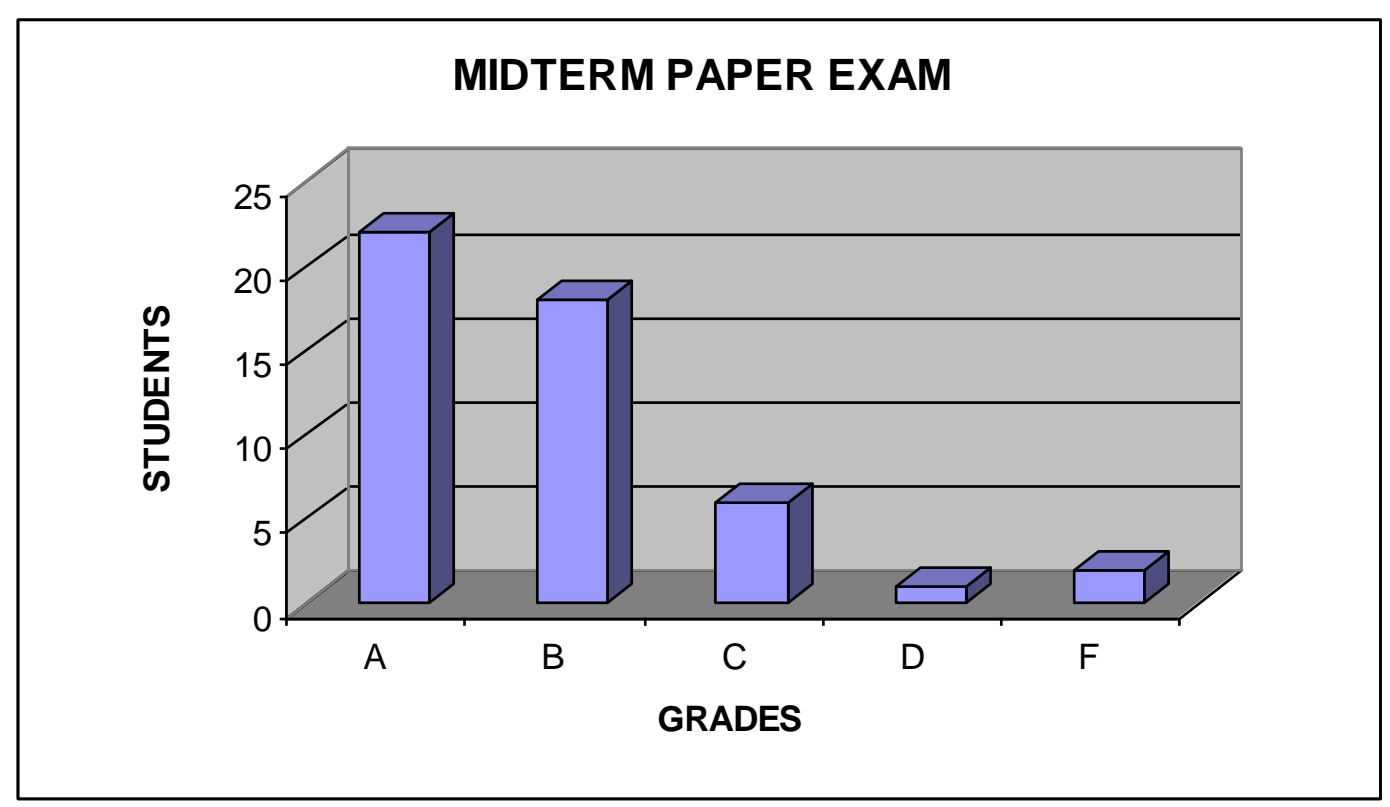

Figure 1 - Midterm Paper Exam 
The Final Exam covered nine chapters of the textbook. The Final Exam also consisted of 60 multiple choice questions generated from a textbook testbank. The exam was generated randomly by the computer portal Blackboard. Each student logged into blackboard to access their exam. The exam allowed the students to have 3 hours to complete it once they started it. Each student was given a unique test with random questions from the nine chapters. The questions were not given in any particular order. Students were given a one week window in which they were allowed to complete the exam but once they started the exam they need had to complete it. The exam was open note and open book but the students were instructed that they were not allowed to use any other outside assistance with the exam. The exams were electronically scored immediately upon submission by the students and the students instantaneously received their scores.

The Final Exam resulted in 26 -As, 13 - Bs, 9 - Cs, 1 - D, and 0 - Fs (See Figure 2).

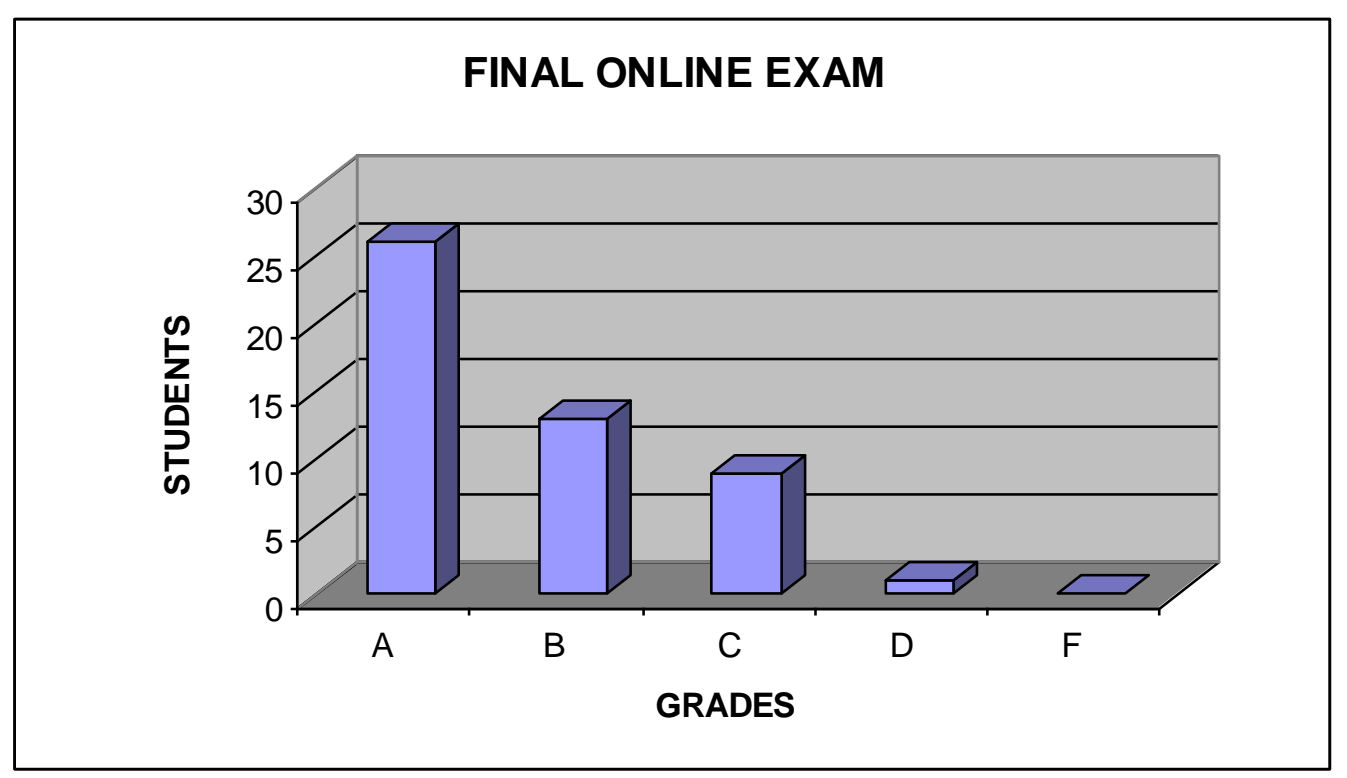

Figure 2 - Final Online Exam

Forty-one percent of the students, which is twenty students, earned the same letter grade on the midterm as the final. For example, if they got an A on the midterm they got an A on the final. Eleven of the students scored one grade lower on the final than the midterm. An additional three students scored two letter grades lower. Therefore, approximately twenty-nine percent of the students performed worse on the Final Exam when compared to the midterm. Thirty-one percent of the students improved their scores on the final over their scores on the midterm. Nine students improved it by one letter grade. Four students improved it by to letter grades. Two students even improved their grade by more than two letter grade.

Furthermore, the differences can be studied further by examining the actual percentage difference in grades (See Figure 3). Forty-five percent of the students scored within five percent on their final of their grade on the midterm. For example, if they scored $88 \%$ on their midterm they have scored between $83 \%$ and $93 \%$. Thirty-one percent of the students had a difference in their scores of 5\% to $10 \%$. Ten percent had a difference in score of $10 \%$ to $15 \%$. Eight percent had a difference in score of $15 \%-20 \%$. Six percent of the students had a difference of more than $20 \%$ in their scores. 


\section{DIFFERENCE IN GRADES}

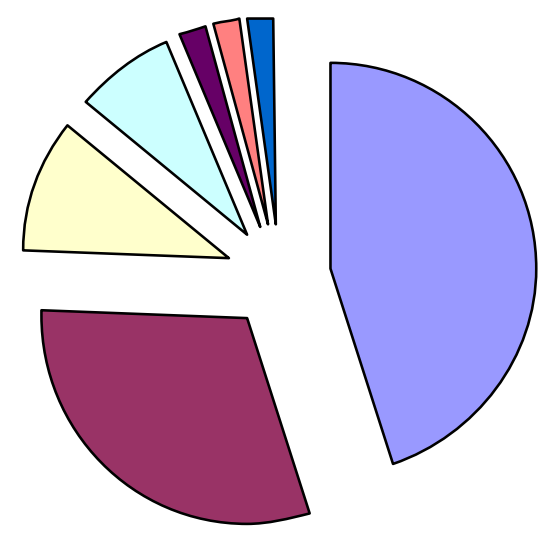

$\square 0-5 \%$

$5-10 \%$

ㅁ $10-15 \%$

$15-20 \%$

$20-25 \%$

$\square 25-30 \%$

$30-35 \%$

Figure 3 - Differences in Midterm and Final Exams Scores

Examining the statistics of the two exams provides more information on the exams (See Figure 4). The midterm and Final Exams resulted in a relatively similar maximum score of an A with a $98 \%$ on the midterm and a $100 \%$ on the final. The minimum is notably different on the midterm from the final. The minimum on the midterm was a $\mathrm{F}$ and on the final the minimum was a $\mathrm{D}$. There is not a considerable difference in the mean or the median scores of the midterm or the final.

\begin{tabular}{|lcc|}
\hline & MIDTERM & FINAL \\
MINIMUM & 58 & 68 \\
MAXIMUM & 98 & 100 \\
MODE & $92 \& 98$ & 93 \\
MEAN & 86.4 & 87.8 \\
MEDIAN & 88 & 90 \\
\hline
\end{tabular}

Figure 4 - Midterm and Final Exam Statistics

\section{Faculty and Student Feedback}

This implementation of an online exam is the first time the instructor ever utilized any exam other than a traditional paper and pencil exam taken with a proctor to oversee the students completing the exam. The instructor indicated the following concerns to the use of an online exam:

- $\quad$ Cheating

- Reliability of technology

- $\quad$ Ease of use for instructor

- $\quad$ Ease of use for students

- Student satisfaction with online exam 
Cheating. The biggest concern for use of an online exam is cheating. With the paper and pencil exam, students are constantly monitored to assure that each student is taking the exam without the assistance of other individuals. By putting the exam online and allowing the students to take the exam at their leisure creates an opportunity for students to get assistance on the exam. The instructor addressed this concern by using a random exam so that each student has a completely different exam so students cannot share answers. The instructor does acknowledge that the random exam does not completely address the issue and the instructor must use the honor system to hope that students do not cheat.

Reliability of technology. The professors indicated that they did have a fear of the reliability of the technology. In order for the students to complete the exam online the students must have access to the internet and $\log$ into blackboard. The implementation of the online exam using blackboard allowed to professor the option of using a randomized test so that every student got a unique test. From the professor's perspective the technology proved to be very reliable although three students had problems they were not due to the technology being unreliable.

Ease of use for instructor. The textbook used by the professor provided a testbank that was compatible with blackboard. This allowed the testbank to be quickly and easily uploaded. The exam can then be created in blackboard with a variety of options. The instructor was able to use the following options on the test:

- $\quad$ Forced completion (students had to complete in one sitting)

- $\quad$ Scheduled availability for the exam

- $\quad$ Number of questions from each chapter

- Total number of questions on the exam

- $\quad$ Time limit for the exam

- $\quad$ Random questions for each student

- $\quad$ Immediate scoring reported to students.

The instructor reported that these options were very easy to incorporate into the exam. The instructor also had the ability to reset an exam and receive statistics including amount of time each student took to take the exam and their scores on the exam throughout the exam as well as at the end of the exam time period.

Ease of use for students. Students are becoming more and more proficient in the use of technology as jobs are now requiring these skills to meet the demands of their everyday job. Three students reported technological problems during the exam.

One indicated that when he submitted the exam he received a message stating that not all questions had answers and did he want to review before submitting but when he reviewed the exam all questions had answers so he submitted anyway. He notified the instructor and the instructor verified that all questions did indeed have answers. When surveying the students after the exam, several students had the same problem. The exam is designed so that a student can save after every question or wait until the end of the exam and save. Several students started saving after each question but when this proved to be extremely time consuming stopped and opted to just save at the end. These are the students that received the missing answer message. The students that saved after each and every question or only at the end did not receive the message.

One student reported that the exam stopped timing her session in the middle of the exam. She therefore indicated that she used the honor system and timed herself to assure she did not go over the three hour time limit. Although, the instructor was not able to determine what caused the student to feel that the timer had stopped, the instructor verified that the timer did in fact work.

The final student had an actual problem taking the exam. While taking the exam the student navigated away from the exam thus preventing her ability to finish the exam. Using the computer for anything else while in the middle of the exam ends the exam session. This aspect although unexpected provides extra reassurance to the instructor that students have fewer opportunities to cheat by access the internet during the exam. With this new knowledge, students can be warned so that they know not to navigate away from the site during the exam. In this case, the instructor was not able to give the student access to the exam she had in progress but was able to reset the 
exam and the student was able to retake the exam from the beginning.

Student Satisfaction. Students were surveyed after completion of both the midterm and Final Exam. Of the fortynine students, an overwhelming forty-one, eighty-four percent, indicated that not only would they like to take an exam online again they stated they would actually prefer it. The other eight students indicated they prefer the traditional paper and pencil exam in a monitored prescheduled setting (see Figure 5).

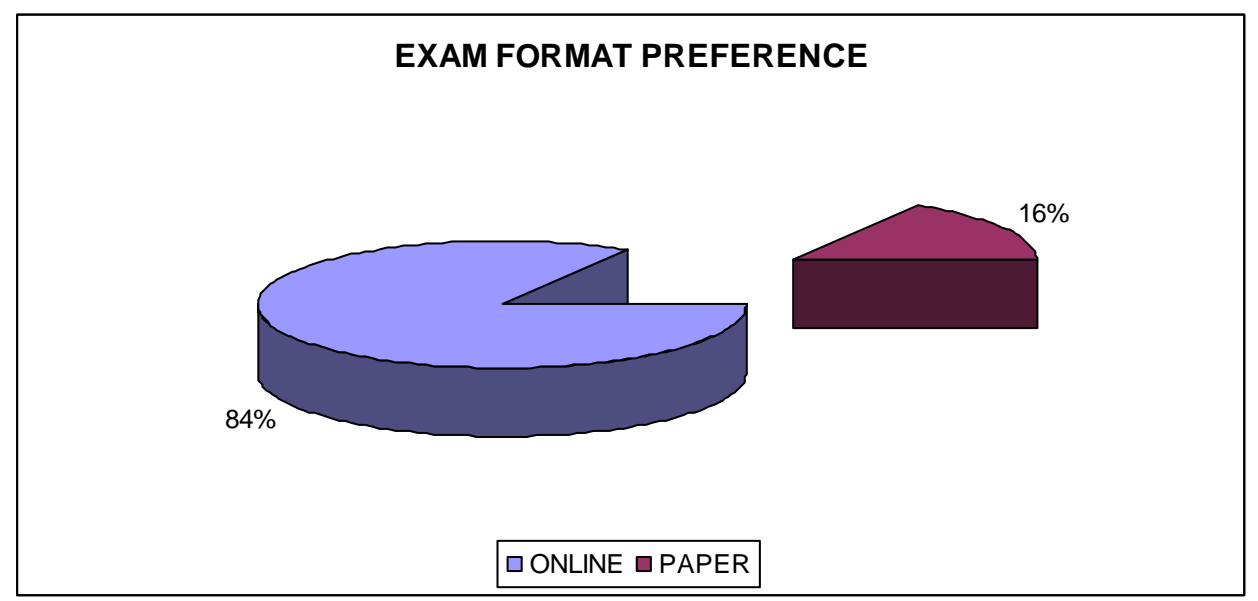

Figure 5 - Student format preference

Students that preferred the online exam shared that the exam reduced some of their stress generally associated and expected when taking an exam. The traditional paper and pen exam required students to take the exam during class time which generally in the evening after a long day of work. Students are tired and distracted from their work day. The online exam allowed students to choose the time and place they took the exam. Many of students particularly like the fact that they could get up on Saturday morning when they were fresh and relaxed and take the exam. In addition, the students really liked the fact that they received their scores instantaneously and did not have to wait a week to get their scores. The online exam was easy to use and many of the students actually felt that the online exam was easier to use. The students indicated that in the traditional paper and pencil exam students have accidently marked an answer on the wrong line on the answer sheet thus messing up all of their answers and even some times greatly affecting their grade on the exam. The format of the online exam prevents this from happening. The few technological problems caused some students to prefer the paper and pencil exam. In addition, a few of the students stated they just prefer things in written form rather than reading everything on a computer screen.

\section{CONCLUSION \& FUTURE IMPLICATIONS}

An online Final Exam was implemented with minor complications resulting in an overall satisfactory experience for both the instructor and students. The specificities of the blackboard online exam that occurred during this implementation provide insight to help alleviate even the minor complications that occurred.

After the online exam has been implemented in more courses it would be beneficial to compare and contrast the scores from the previous courses that were paper and pencil with the scores from the newly administered online exams to determine if there is a significant difference in student outcomes. In addition, instructors need to continue to monitor and evaluate the issue of cheating on online exams and find safeguards against such behavior. 


\section{AUTHOR INFORMATION}

Stacy M.P. Schmidt, Ed.D. is an Associate Professor at California State University, Bakersfield. Dr. Schmidt is a professor in the Teacher Education Department. She is the TPA Coordinator and Secondary Education Program Coordinator for the offsite campuses located in Antelope Valley and College of the Canyons.

David L. Ralph, Ph.D. is a Professor at Pepperdine University. Dr. Ralph is a Professor of Marketing for the Graziadio School of Business and Management. He is the Discipline Lead for the Marketing Department.

Bruce Buskirk, Ph.D. is a Professor at Pepperdine University. Dr. Buskirk is a Professor of Marketing for the Graziadio School of Business and Management.

\section{REFERENCES}

1. Bugeja, M. (2007). Distractions in the Wireless Classroom. Chronicle of Higher Education, 53,

2. $\quad$ Connors, S. (2007). $21^{\text {st }}$ Century Tools, Phi Delta Kappan, 89, 320.

3. Hale, S. (2007). Being Online. Academe, 93.

4. Hay, I. \& Bull, J. (2002). Passing Online Exams. Journal of Geography in Higher Education, 26, 239244.

5. How Professors Are Using Technology: a Report From the Trenches. (2007) Chronicle of Higher Education, 54, pB21-B23.

6. Luecht, R. M. (2001). Challenges of web-based assessment. American Educational Research Association Proceedings, Seattle, WA.

7. Patterson, D. (2006). A large-scale, Asynchronous, Web-based MSW Comprehensive Exam Administration:Outcomes and Lesson s Learned. Journal of Social Work Education, 42, 14.

8. Ralph, D. L., Buskirk, B. D., Schmidt, S. M.P. (2007). Online Projects VS the 3 Ring Binder: A Case Study. The Business Review, Cambridge, 9, 106-111.

9. Rowh, M. (2007). E-Learning: The Anytime, Anywhere Option._Career World, 36, 22-25.

10. Schmidt, S. M. P., Ralph, D. L., \& Buskirk, B. (2006) E-Portfolios: Improving Education or a Cumbersome Fad? College Teaching and Learning Conference Proceedings, Electronic Publication.

11. Steinman, D. (2007). Educational Experiences and the Online Student. TechTrends: Linking Research \& Practice to Improve Learning, 51, 46-52.

12. Walker, C. \& Kelly, E. (2007). Online Instruction: Student Satisfaction, Kudos, and Pet Peeves. Quarterly Review of Distance Education, 8, 11. 